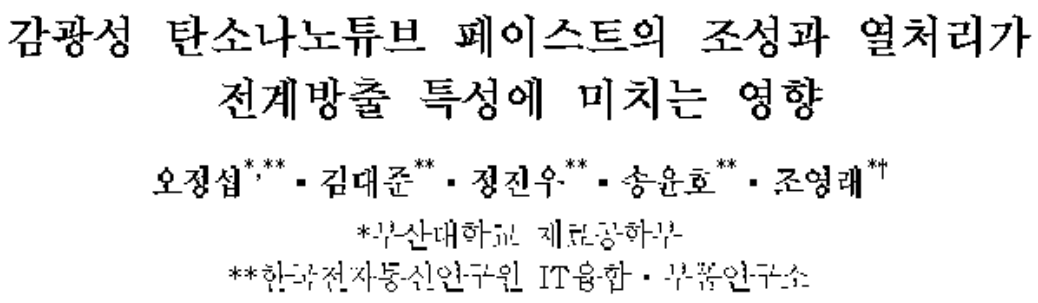

\title{
Effect of Photosensitive Carbon Nanotube Paste on Field Emission Properties
}

\author{
Jeong-Seob $\mathrm{Oh}^{* * * *}$, Dae-Jun Kim ${ }^{* *}$, Jin-Woo Jeong ${ }^{* *}$, Yoon-Ho Song ${ }^{* *}$ and Young-Rae Cho ${ }^{*+}$ \\ *Division of Materials Science and Engineering, Pusan National University, Busan, 609-735 \\ **IT Convergence \& Components Laboratory, Electronic and Telecommunications Research Institute
}

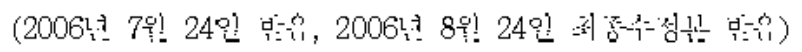

\begin{abstract}
Photosensitive carbon nanotube (CNT) pastes are explored to develop a CNT field emitter for field emission display (FED) application. We formulated a photosensitive paste including multi-walled CNTs (MWNTs) for screen printing. The photosensitive CNT paste was synthesized by mixing of MWNTs, inorganic fillers (nano metal), organic vehicle, monomers and photo initiator. The CNT paste films were patterned by using backside exposure technique. The CNTs were strongly fixed on a cathode by formation of carbon residue during firing process. For the CNT emitters, current-voltage(I-V) characteristics and images of field emission were evaluated. The emission properties of CNT emitters are dependent on the paste composition. A turn-on electric field for the CNT field emitters is measured to be $1 \mathrm{~V} / \mu \mathrm{m}$. Additionally, the effect of heat treatment parameter on field emission properties was discussed. The newly formulated photosensitive CNT paste can be potentially applicable to highly reliable CNT field emitters.
\end{abstract}

Key words photosensitive paste, carbon nanotube, field emission, CNT emitter, backside exposure.

\section{1. 서 론}

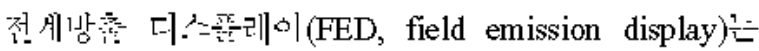

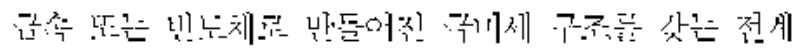

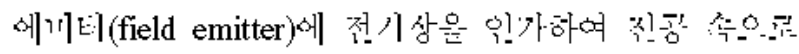

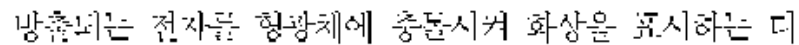

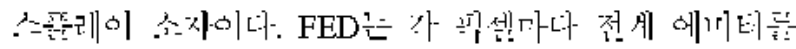

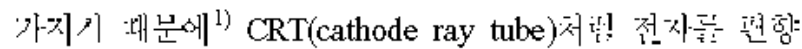

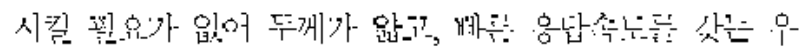

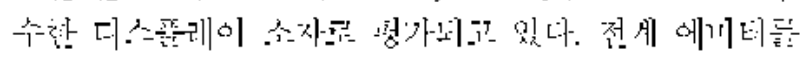

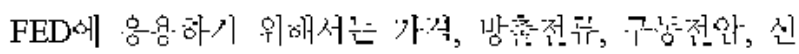

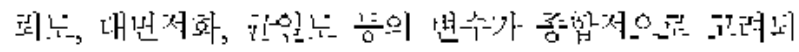
어야 한다.

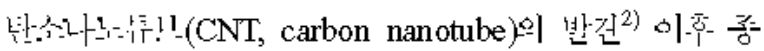

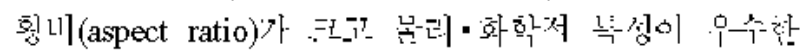

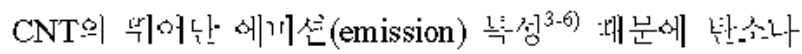

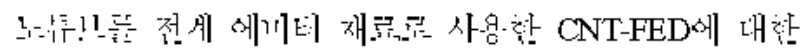

${ }^{\dagger} \mathrm{E}-\mathrm{Mail}$ : yescho@pusan.ac.kr

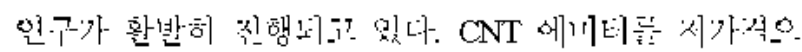

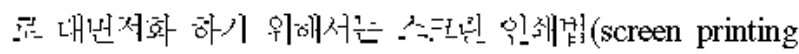

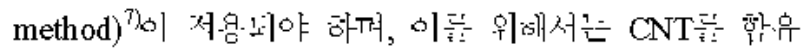

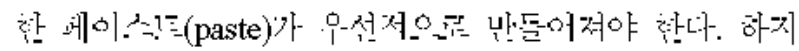

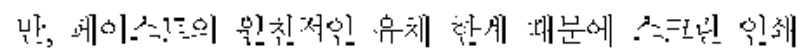

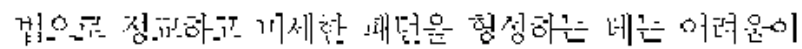

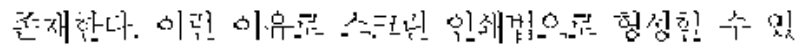

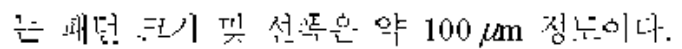

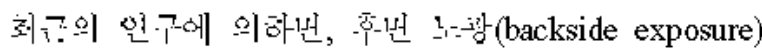

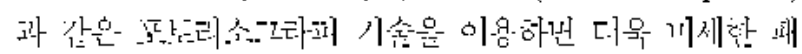

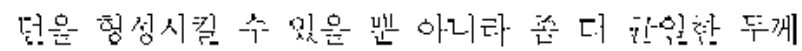

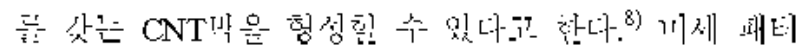

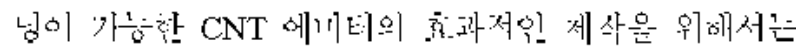

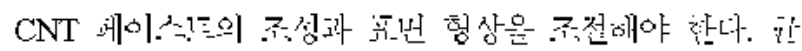

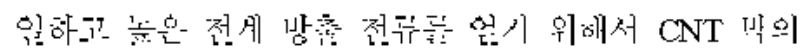

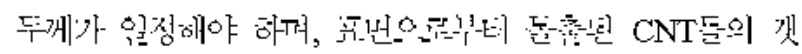

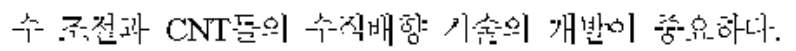

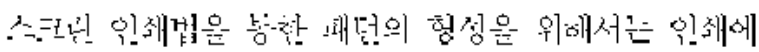

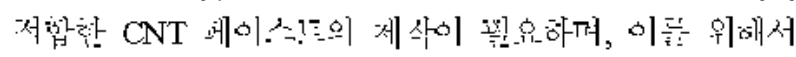


는 유기 바인더(organic binder, 이하 바인더)가 사용된다. 바인더가 가져야 되는 필수 조건은 유기 용매에서 높은 용해도와 상온에서 적당한 점성을 가져야 하며 낮은 온 도에서 분해되어야 한다. 또한, 바인더를 완벽하게 제거 하기 위해서는 알맞은 소성 온도의 설정이 중요하다. 폐 이스트의 또 다른 성분인 무기 충전제(inorganic filler)는 소성 후 $\mathrm{CNT}$ 를 고정시키고 전계방출 특성에 중요한 역 할을 담당한다. 그러므로 $\mathrm{CNT}$ 에미터의 전계방출 균일 도 및 신뢰성을 항상시키기 위해서는 바인더 및 무기 충 전제의 선택과 함량 조절이 동시에 이루어져야 하며 소 성 온도 설정이 병행되어야 한다.

본 연구에서는 나노 금속(nano metal)의 무기 충전제 (filler)를 사용하여 미세한 패턴 형성이 가능한 감광성 (photosensitive) 페이스트를 우선 제조하였다. 제조된 $\mathrm{CNT}$ 페이스트를 사용해서 $\mathrm{CNT}$ 캐소드를 제작할 때, 폐 이스트의 조성과 열처리 조건이 $\mathrm{CNT}$ 캐소드의 전계방 출 특성에 미치는 영향에 대하여 연구하였다. 또한, CNT 캐소드의 전계방출에 대한 가속실험을 통하여 제조된 CNT 에미터의 안정성 및 신뢰성에 대한 연구도 수행하 였다.

\section{2. 실험 방법}

본 연구에 사용된 캐소드용 에미터 재료인 CNT는 CVD 방법으로 합성되었으며, 화학적으로 정제된 다중벽 탄소나노튜브(MWNT) 분말을 사용하였다. MWNT 분말 의 순도는 $95 \mathrm{wt} \%$, 지름은 $4 \sim 6 \mathrm{~nm}$, 길이는 $10 ~ 20 \mu \mathrm{m}$ 정 도였다. CNT를 $20,000 \mathrm{rpm}$ 이상의 속도를 가지는 고속 혼합기를 이용하여 IPA(Isopropyl alcohol)에 분산시켰다. 바인더는 테피네올 $(\alpha$-Terpineol)과 아크릴레이트(Acrylate) 계열의 재료를 혼합하여 제조하였다. 또한, 감광성 $\mathrm{CNT}$ 페이스트의 구현을 위하여 $\mathrm{CNT}$ 와 바인더, 무기 충전제 를 혼합 후 광중합(photo polymerization)을 위해서 광개 시제(photo initiator), 광중합성 단량체(monomer)를 추가 하였다. 혼합이 끝난 조성은 3롤 밀(3-Roll mill)을 이용해서 $\mathrm{CNT}$ 페이스트가 제조되었다. 제조된 $\mathrm{CNT}$ 페이스 트의 대표적인 조성은 Fig. 1에 나타낸 바와 같다.

각각의 제조된 CNT 페이스트는 투명전극(ITO, indium tin oxide)이 코팅된 $58 \times 37 \mathrm{~mm}$ 인 소다라임 유리(sodalime glass) 기판에 크기가 $300 \times 250 \mu \mathrm{m}$ 인 도트 $(\mathrm{dot})$ 형 미세 패턴으로 스크린 인쇄하였으며, 인쇄된 CNT 패턴 의 면적은 약 $1 \mathrm{~cm}^{2}$ 로 계산되었다. 또한, 인쇄된 $\mathrm{CNT}$ 패턴을 ITO전극에 균일한 두께로 고착시키기 위하여 패 턴 된 $\mathrm{CNT}$ 막을 건조시킨 후 각각의 페이스트 조성에 적 합한 노광 조건으로 후면 노광을 실시하였다. 이어서 현 상 공정을 통하여 노광 된 깊이보다 두꺼운 부분의 $\mathrm{CNT}$ 막을 제거 함으로서 균일한 두께의 CNT막을 제조하였다.

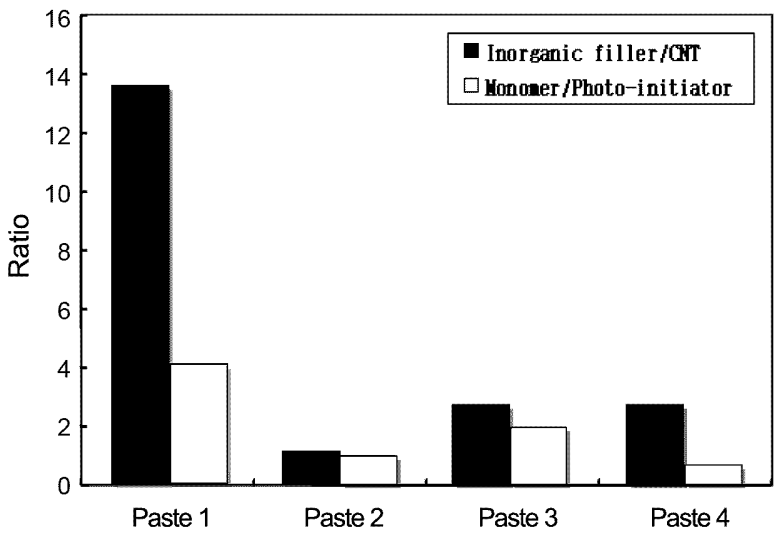

Fig. 1. CNT paste with various compositional ratios.

이어서 시편의 건조 후 전기로(furnace)를 이용하여 $300^{\circ} \mathrm{C}$ 대기분위기에서 1 차 소성을 하였다. 에미터 재료 인 $\mathrm{CNT}$ 를 표면으로 수직 돌출(protrusion) 시키기 위해 기계적인 방법 ${ }^{9}$ 을 이용하여 표면처리도 하였다. 표면처리 후 바인더를 탄소화시키기 위하여 진공분위기 ( 10 $\left.0^{-5} \mathrm{Torr}\right)$ 에서 2차 소성을 하였다.

전계방출 특성의 측정은 고진공 챔버 내에서 2 극형 모 드(diode-type)로 수행하였다. 캐소드(cathode)와 아노드 (anode)의 일정한 간격 유지를 위해 $300 \mu \mathrm{m}$ 의 비전도성 스페이서(spacer)를 사용하였다. 측정 시 챔버내의 진공 도는 대략 $5 \times 10^{-5}$ Torr 정도였다. 전압소스(voltage source)와 전류계를 CNT 캐소드와 아노드로 이루어진 소 자에 직렬로 연결하여 회로를 구성하였으며, 고전압에서 의 순간적인 아크(arc) 발생으로 인한 소자 및 계측장비 의 보호를 위하여 $200 \mathrm{k} \Omega$ 의 저항을 회로에 직렬로 연 결하였다. 전계방출 측정이 끝난 시편에 대하여 주사전 자현미경(FE-SEM, field emission-scanning electron microscope)을 사용해서 CNT 에미터의 형상과 분포 등 을 관찰하였으며 열중량분석(TGA, thermo-gravimetric analyzer)을 이용하여 바인더 성분 등의 온도에 따른 질 량 변화를 분석하였다.

\section{3. 결과 및 고찰}

\subsection{CNT 페이스트의 최적화와 전계방출 특성}

Fig. 2 는 페이스트 1 부터 4 까지의 전계-전류밀도 톡성 곡선 및 Fowler-Nordheim(F-N) plot을 보여주고 있다. 최적화된 조성을 가지는 페이스트 4의 경우 Fig. 2(a)에 서 보듯이, $1 \mathrm{~V} / \mu \mathrm{m}$ 의 전계(electric field)에서 방출 전류 밀도가 대략 $0.8 \mathrm{~mA} / \mathrm{cm}^{2}$ 로 나타났다. Fig. 2(b)의 F-N plot에서 페이스트 4 의 기울기는 선형적인 것으로 나타 나는데, 이것은 전계방출에 의한 현상임을 의미한다. 또 한, 동일한 전계에서 페이스트 4의 방출전류가 가장 크 

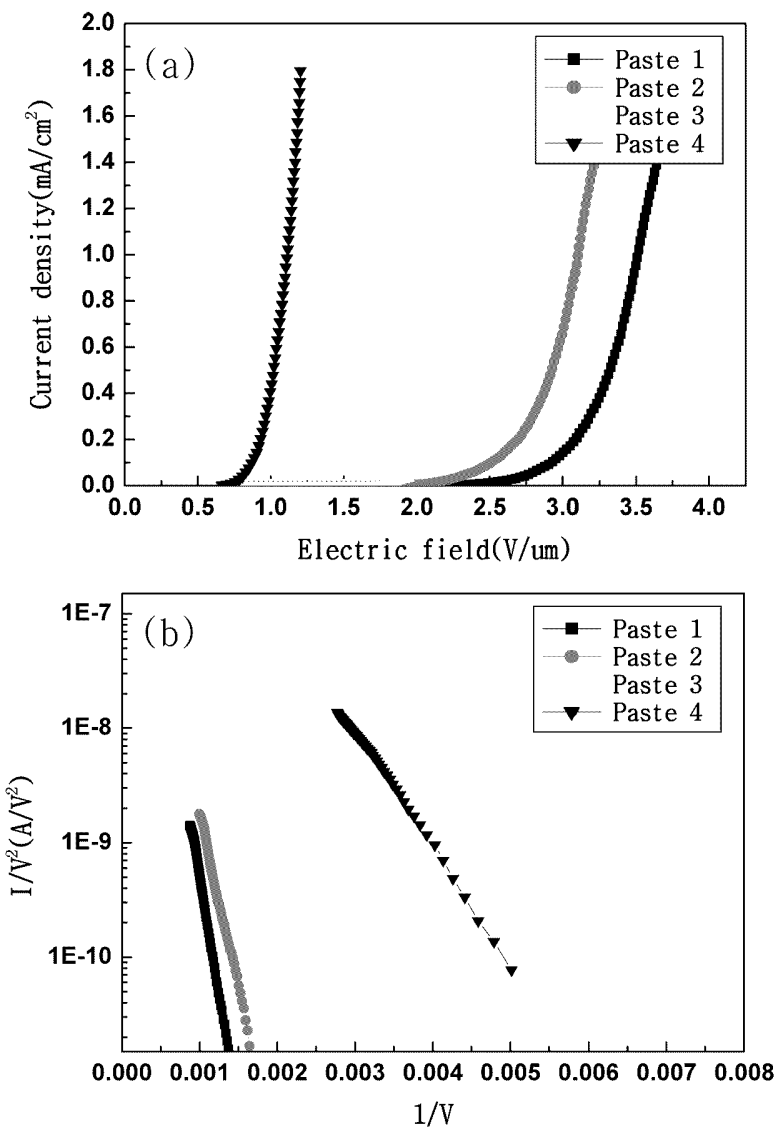

Fig. 2. (a) Field emission characteristics of CNT cathodes from paste 1 to optimized paste 4, (b) corresponding FowlerNordheim plots.
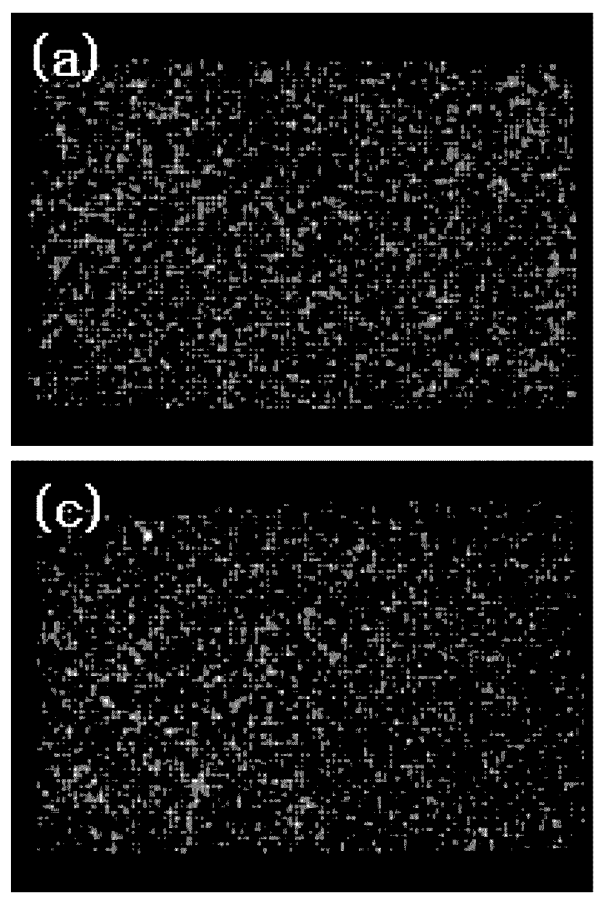

게 나타나는데, 이는 페이스트 4의 화학적 조성과 물리 적 표면 형상이 최적화되어 이를 통해 에미터의 전기적 특성의 향상이 이루어졌음을 뜻한다. ${ }^{10)}$

Fig. 3은 제조된 4가지의 페이스트를 사용한 CNT 에 미터의 발광 이미지를 나타낸 것이다. Fig. 3(a) 3(c)에 서는 불균일한 전계방출에 의한 이미지가 관찰되는데 비 하여, 페이스트 4에 해당하는 Fig. 3(d)에서는 CNT가 패 턴 된 면적 전체에서 균일하게 발광되었다. 전계방출 이 미지에서 밝기가 불균일하게 나타나는 이유 ${ }^{11)}$ 는 표면으 로부터 돌출된 $\mathrm{CNT}$ 의 높이가 다르고 $\mathrm{CNT}$ 의 분포가 균 일하지 않아서, 전계방출에 기여하는 CNT 에미터의 밀 도가 각각 다르기 때문이다.

Table 1은 F-N plot으로부터 계산된 값을 정리하여 나 타넨 실험결과이다. 전계증배계수 $(\beta$, field enhancement factor)는 전계방출에서 에미터의 유효 일함수(work function)를 알 수 있는 지표이다. 페이스트 4를 사용한 시편에서 $\beta$ 값은 22,874 로 다른 3 가지의 페이스트를 사

Table 1. Field emission parameters of the slope $\mathrm{m}$, the field enhancement factor $\beta$, intercept $\mathrm{b}$ and the effective emission area $\mathrm{A}$ are derived from the F-N plot.

\begin{tabular}{ccccc}
\hline \hline Sample & $\mathrm{m}$ & $\beta$ & $\mathrm{b}$ & $\mathrm{A}\left[\mathrm{cm}^{2}\right]$ \\
\hline Paste 1 & -4008.7 & 5715 & -5.339 & $4.83 \times 10^{-9}$ \\
Paste 2 & -3220.3 & 7114 & -5.536 & $2.56 \times 10^{-9}$ \\
Paste 3 & -3018.5 & 7589 & -5.145 & $3.33 \times 10^{-9}$ \\
Paste 4 & -1001.5 & 22874 & -5.085 & $3.89 \times 10^{-9}$ \\
\hline
\end{tabular}
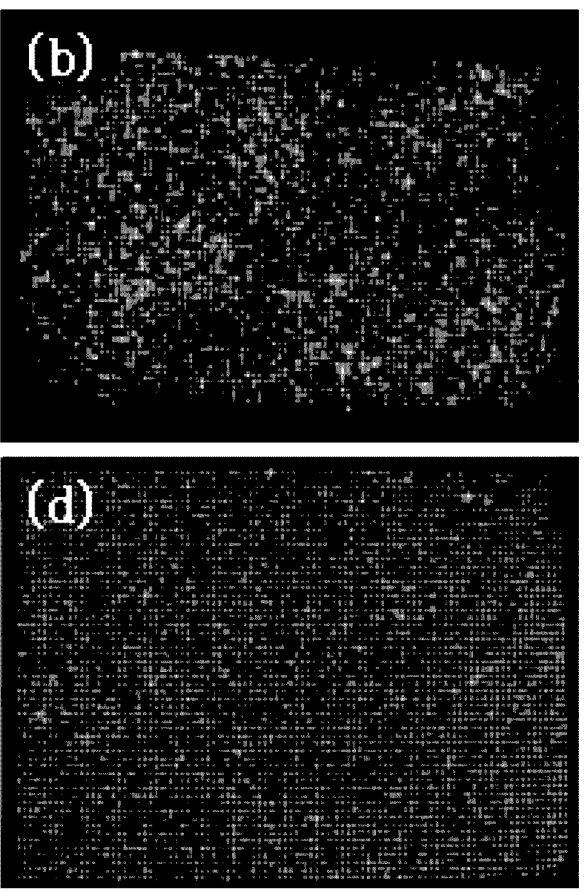

Fig. 3. Field emission images by (a) paste 1, (b) paste 2, (c) paste 3 and (d) optimized paste 4. 
용한 시편에서 보다 가장 높게 나타났다.

$$
\beta=\mathrm{Bd} \phi^{3 / 2} / \mathrm{S}
$$

여기서 $\beta$ 는 전계증배계수, $\mathrm{B}$ 는 $-6.83 \times 10^{9}\left[\mathrm{VeV}^{3 / 2} / \mathrm{m}\right]$, $\mathrm{d}$ 는 anode와 cathode 사이의 거리, $\varphi$ 는 $\mathrm{CNT}$ 의 work function $(\fallingdotseq 5 \mathrm{eV})$ 를 나타낸다. ${ }^{12)}$

식 (1)을 참고하여 Table 1에서 보듯이 페이스트 4는 $\mathrm{F}-\mathrm{N}$ 기울기가 다른 페이스트보다 작기 때문에 큰 $\beta$ 값 을 갖는다. 이것은 동일한 외부 전압을 인가할 경우 페 이스트 4를 사용한 시편에서 가장 큰 전계방출 전류가 관찰됨을 의미한다. 실험결과에 의하면, 페이스트 4 를 사 용한 시편의 경우 동일한 전압에서 방출전류가 가장 높 았으며, 전계방출 또한 안정적으로 나타났다.

$\mathrm{CNT}$ 의 일함수가 $5 \mathrm{eV}$ 로 동일하다는 가정하에 $\mathrm{F}-\mathrm{N}$ 식 을 이용하면 유효 방출면적(effective emission area)을 계 산할 수 있으며, F-N 식 ${ }^{13)}$ 및 유효 방출면적 ${ }^{14)}$ 은 다음 과 같이 나타넨다.

$$
\mathrm{I}=\mathrm{aV} \mathrm{V}^{2} \exp (-\mathrm{b} / \mathrm{V})
$$

$$
\begin{aligned}
& \text { 여기서 } \\
& \begin{array}{l}
\mathrm{a}=\left(1.56 \times 10^{-6} \beta^{2} \mathrm{~A} / 1.1 \phi\right) \exp \left(10.4 / \phi^{1 / 2}\right) \\
\mathrm{b}=6.44 \times 10^{7} \phi^{3 / 2} / \beta
\end{array}
\end{aligned}
$$

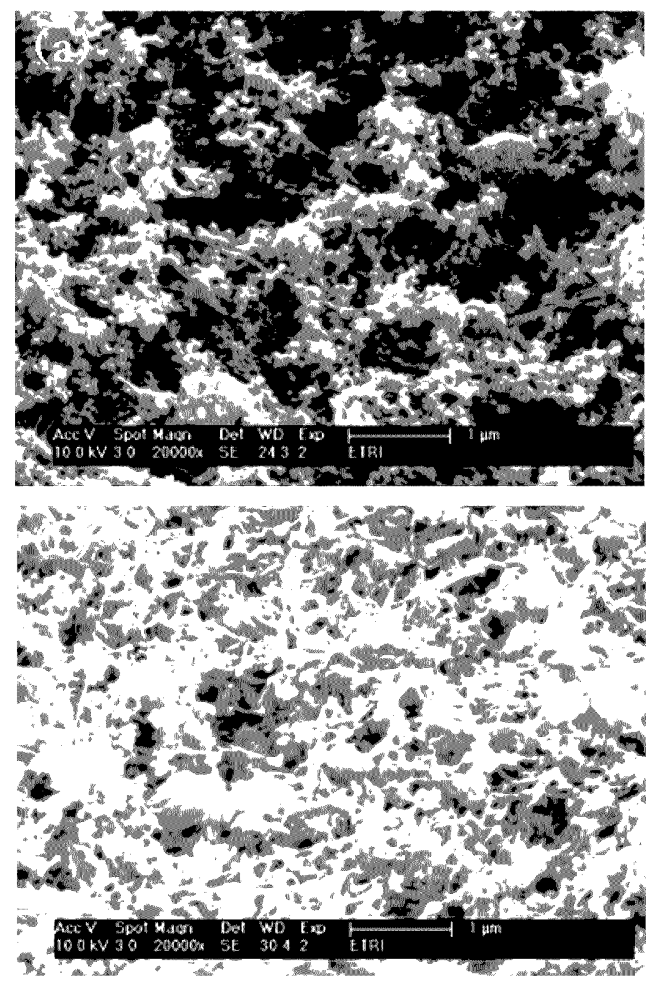

이때, $\mathrm{A}$ 는 전계방출 면적, $\Phi$ 는 $\mathrm{CNT}$ 의 일함수, $\beta$ 는 전계증배계수이다. 이 식에서 우세한 항은 지수항으로서 전계가 증가하고 일함수가 감소하면 전류(I)는 매우 급 격히 증가한다는 것을 알 수 있다.

$$
\mathrm{A}=1.67356 \times 10^{-14}\left(\mathrm{~m}^{2} / \phi^{2}\right) \exp \{\mathrm{b}-(10.441 / \sqrt{\phi})\}\left[\mathrm{m}^{2}\right]
$$

여기서 $\mathrm{m}$ 과 $\mathrm{b}$ 는 $\mathrm{F}-\mathrm{N}$ plot의 기울기 및 $\mathrm{y}$ 축 절편을 의 미한다. 본 연구에서는 Table 1에서 보듯이 페이스트 1 에서 가장 큰 유효 방출면적이 계산되었다. 페이스트 1 에서 가장 큰 유효방출 면적이 나타난 이유는 유효 방출 면적은 F-N plot 기울기의 제곱에 비례하기 때문이다. 가 장 적합한 $\mathrm{CNT}$ 에미터는 낮은 인가전압에서 균일하고 밝은 이미지를 내는 것이다. 이런 이유로 전계 증배계수 및 유효 방출면적, 발광영역의 균일도 등의 종합적인 면 을 고려했을 때 페이스트 4가 최적화된 페이스트 조성 으로 판단하였다.

Fig. 4는 각각의 페이스트 조성에 대한 $\mathrm{CNT}$ 막의 $\mathrm{SEM}$ 사진을 보여주고 있다. Fig. 4(d)에서 CNT가 수직 적인 방향으로 존재하는 것이 많이 관찰되며 $\mathrm{Fig}$. 4(a) 4(c)까지는 바인더 등이 CNT 표면 주위에 많이 묻 어 있는 것을 발견할 수 있다. CNT 표면에 바인더 등 의 불순물이 묻어 있으면 일함수(work function)의 증가 를 야기하기 때문에, 결국은 문턱전계(turn-on field)가 상
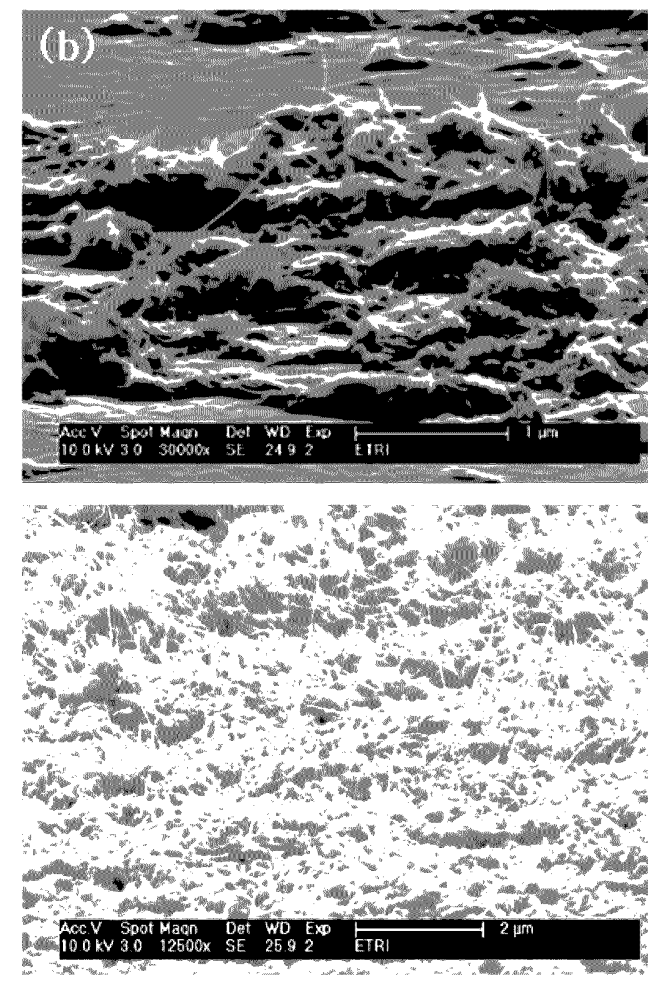

Fig. 4. SEM images of CNT film after surface treatment for (a) paste 1, (b) paste 2, (c) paste 3, (d) paste 4 with the optimized composition. 
승하고 전계방출이 안정적으로 나타나지 않는다. ${ }^{15}$

\section{2 소성 최적화 및 신뢰성 분석}

최적화된 조성을 가지는 페이스트 4를 이용하여 소성 최적화 및 에미터의 신뢰성 특성을 평가하였다. Table 2 는 시편의 종류별 기호를 소성조건과 연관시켜 나타낸 것 이다.

Fig. 5 는 후면 노광의 장점 및 2 차 소성의 필요성을 증명하기 위해서 소성온도 조건에 따른 아노드 전류밀도 변화를 실시간으로 측정한 결과이다. Table 3에서 보듯 이 $2 \mathrm{~F} 350 \mathrm{~V}$ 시편의 경우 1 시간 동안의 전계방출 후 전 류밀도 값이 $1.09 \%$ 로 가장 적게 감소하였다. 이 결과는 타 연구팀의 결과 ${ }^{16)}$ 에 비해 초기 전류밀도의 감소율이 적 은 것을 확인할 수 있었다. 이것은 $2 \mathrm{~F} 350 \mathrm{~V}$ 시편의 $\mathrm{CNT}$ 에미터가 다른 소성 조건의 시편들에 비교하여 CNT 팁 (tip)의 화학적인 상태가 양호하다는 것을 의미한다.

Fig. 6은 최적화된 $\mathrm{CNT}$ 페이스트 4의 $\mathrm{TGA}$ 결과이다. TGA 결과를 보면 크게 3 가지 영역으로 나눌 수 있다. 제 1 영역은 용매가 증발되는 영역이며, 제 2 영역은 바인

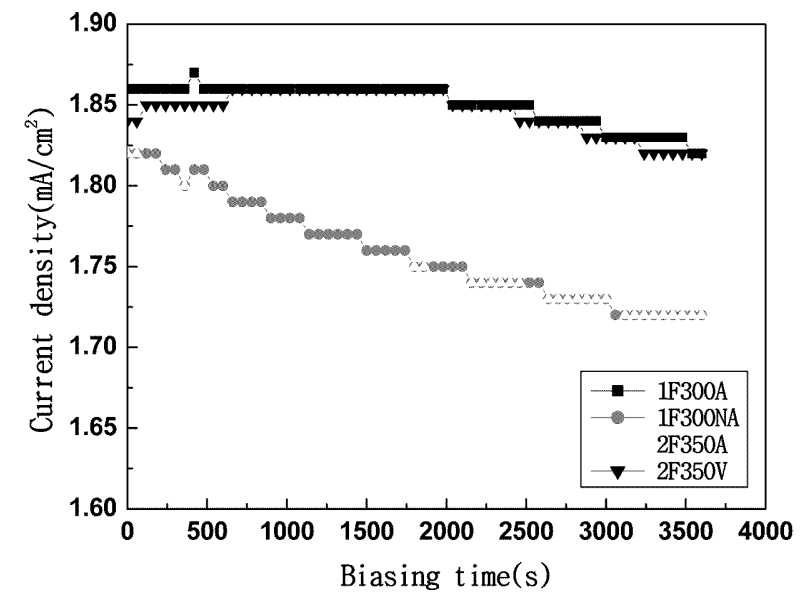

Fig. 5. Anode current densities as a function of time under a DC operation for the various firing conditions.

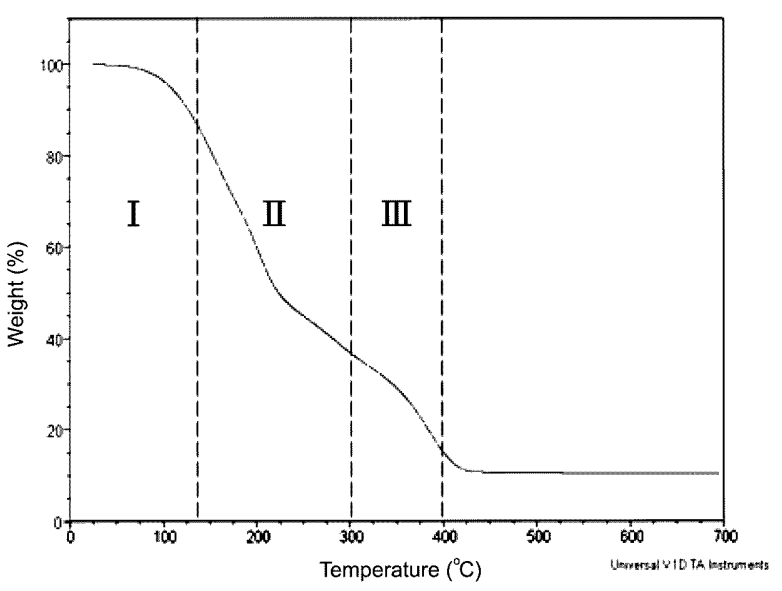

Fig. 6. TGA curve of the optimized CNT paste (paste 4).

더가 대부분 제거(burn out)되는 영역이고, 제 3 영역은 CNT 에미터의 고정을 위해 탄소화가 이루어지는 영역이 다. 일반적으로 CNT 에미터 형성을 위한 소성은 원하는 특성 확보를 위하여 다른 온도와 분위기에서 2단계로 실 시한다. ${ }^{17)} 1$ 차 소성으로 $\mathrm{CNT}$ 표면에 모노 층(mono layer) 으로 코팅된 유기물을 제거하고, 고진공 $\left(\sim 10^{-5} \mathrm{Torr}\right)$ 에서 2 차 소성을 수행하여 나노 금속의 부분적인 용융 및 바 인더의 탄소화를 통해 CNT의 접착성을 유지하며, 폐이 스트 내부에 잔존하는 가스를 탈가스(degas) 시킬 수 있 기 때문에 안정된 전계방출 현상을 얻을 수 있었다. ${ }^{14)}$

Fig. 7에서는 소성온도 조건 변화에 따른 SEM 사진 을 보여주고 있다. 스크린 인쇄된 페이스트의 두께를 보 면 후면 노광 기술을 적용한 시편(Fig. 7(a))이 적용하지 않은 시편(Fig. 7(b))보다 간일한 두께(약 $2.5 \mu \mathrm{m}$ )를 보 였다. 동일한 온도인 $350^{\circ} \mathrm{C}$ 에서 2단계로 열처리한 Fig. 7(c)와 Fig. 7(d)를 비교해보면 Fig. 7(d) 시편에서는 잔 여 바인더가 탄소화 된 모습을 보여주는 반면 Fig. 7(c) 에서는 탄소화 된 모습이 관찰되지 않았다. 그리고 $\mathrm{CNTs}$ 표면에 붙은 불순물도 Fig. 7(d) 시편이 가장 적었기 때 문에, 소성의 최적조건은 대기분위기에서 $300^{\circ} \mathrm{C}$ 까지 1 차

Table 2. Designation of samples for firing of CNT paste 4.

\begin{tabular}{cll}
\hline \hline Sample & \multicolumn{1}{c}{ Condition } & Ambiance \\
\hline $1 \mathrm{~F} 300 \mathrm{~A}$ & 1 st firing at $300^{\circ} \mathrm{C}$ & Air \\
$1 \mathrm{~F} 300 \mathrm{NA}$ & 1 st firing-No U.V exposure at $300^{\circ} \mathrm{C}$ & Air \\
$2 \mathrm{~F} 350 \mathrm{~A}$ & 1 st firing +2 nd firing at $300^{\circ} \mathrm{C} / 350^{\circ} \mathrm{C}$ & Air $/$ Air \\
$2 \mathrm{~F} 350 \mathrm{~V}$ & 1 st firing $+2 \mathrm{nd}$ firing at $300^{\circ} \mathrm{C} / 350^{\circ} \mathrm{C}$ & Air/Vacuum \\
\hline
\end{tabular}

Table 3. Anode current density changes for various firing conditions.

\begin{tabular}{lcccc}
\hline \hline & $1 \mathrm{~F} 300 \mathrm{~A}$ & $1 \mathrm{~F} 300 \mathrm{NA}$ & $2 \mathrm{~F} 350 \mathrm{~A}$ & $2 \mathrm{~F} 350 \mathrm{~V}$ \\
\hline Initial current density & $1.86 \mathrm{~mA} / \mathrm{cm}^{2}$ & $1.82 \mathrm{~mA} / \mathrm{cm}^{2}$ & $1.82 \mathrm{~mA} / \mathrm{cm}^{2}$ & $1.84 \mathrm{~mA} / \mathrm{cm}^{2}$ \\
After 1 hour & $1.82 \mathrm{~mA} / \mathrm{cm}^{2}$ & $1.72 \mathrm{~mA} / \mathrm{cm}^{2}$ & $1.72 \mathrm{~mA} / \mathrm{cm}^{2}$ & $1.82 \mathrm{~mA} / \mathrm{cm}^{2}$ \\
Decreased ratio & $2.15 \%$ & $5.49 \%$ & $5.49 \%$ & $1.09 \%$ \\
\hline
\end{tabular}



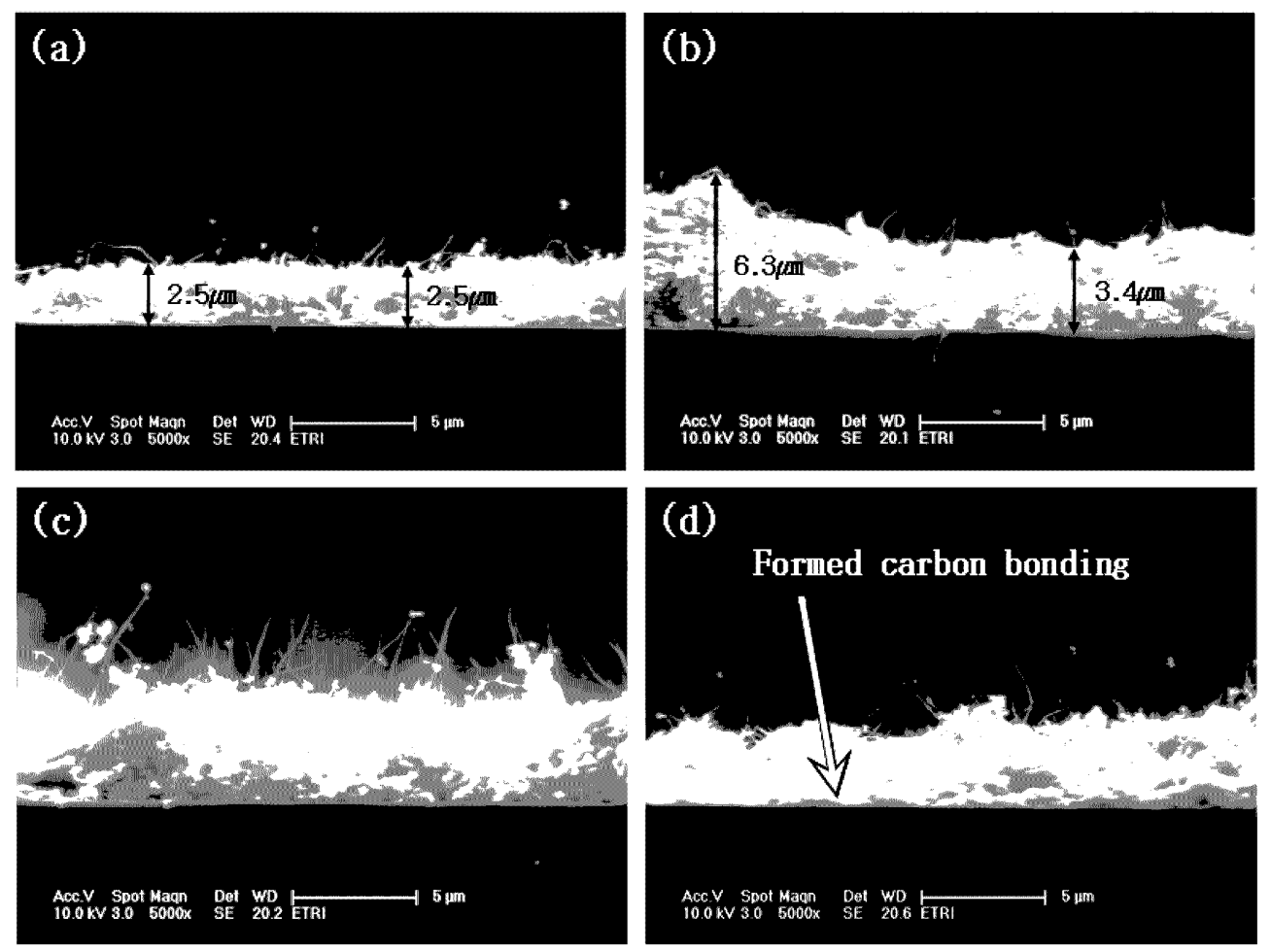

Fig. 7. SEM images of CNT cathodes with different heat treatments: (a) $1 \mathrm{~F} 300 \mathrm{~A}$, (b) $2 \mathrm{~F} 350 \mathrm{~V}$, (c) $1 \mathrm{~F} 350 \mathrm{~A}$ and (d) $1 \mathrm{~F} 300 \mathrm{NA}$.

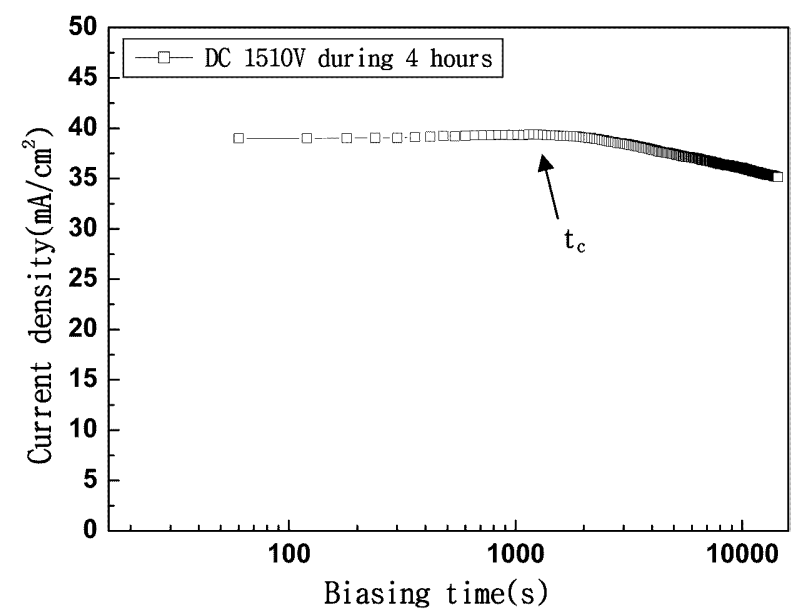

Fig. 8. Anode current density as a function of time under a DC voltage of $1510 \mathrm{~V}$ for $4 \mathrm{~h}$ operation for the optimized CNT emitters.

소성 후 $350^{\circ} \mathrm{C}$ 까지 진공분위기에서 2 차 소성하는 것으 로 결정하였다.

Fig. 8은 최적화된 페이스트의 조성과 최적의 소성 온 도로 만든 CNT 에미터의 신뢰성 테스트를 위해서 연속 적인 직류(DC) 조건의 전계로 챔버(chamber) 내에서 2 극형 모드(diode-type)로 전계방출 실험한 결과를 보여주 고 있다. 일반적으로 에미션 시간의 증가와 함께 방출 전
류밀도는 감소한다. 그러나 본 연구의 최적화된 조건으 로 만들어진 $\mathrm{CNT}$ 에미터는 일정시간까지 전류밀도의 변 화가 거의 일어나지 않았다. 즉, $1510 \mathrm{~V}$ 의 고정전압에서 4시간 동안 측정시 아노드 전류밀도는 $9.93 \%$ 의 아주 작 은 감소율을 보인다. 전류밀도 변화가 없는 1000 초 까 지를 임계시간(tc, critical biasing time)이라 정의할 수 있으며, 본 연구의 결과는 종래의 연구결과에 비하여 $\mathrm{CNT}$ 에미터의 수명이 상당히 길다는 것을 의미한다.

$\mathrm{CNT}$ 캐소드에서 에미터의 수명은 동일한 전압의 인 가시 동작시간 증가에 따라 방출전류가 감소되는 양으로 퐌단하며, 초기 전류 대비 방출전류가 $50 \%$ 로 출어드는 시간을 에미터의 수명으로 규정하기도 한다. 방출전류가 감소하는 이유로는 전계방출시 열에 의해서 에미터가 손 상되기 때문으로 알려져 있다. CNT의 경우 발열 과정 기 구는 크게 주울열(Joule heating)과 노팅햄 에너지 변환 (Nottingham energy transfer)의 두 가지로 대별할 수 있 다. 전자의 경우 격자진동(lattice vibration)이 발열로 이 어지는 경우며 후자는 tip과 같이 국부적인 돌출부위에서 전자방출과 정공의 에너지 준위 채움에 관련 된다. 본 연 구의 전계 방출에 관련된 전류 값은 CNT 에미터 1개 당 $1 \mu \mathrm{A}$ 이하로 낮은 경우에 해당되므로 격자진동으로 인한 주울 효과보다는 노팅햄 효과가 지배적이다. 따라 서 에미터 손상으로 인한 미소한 방출전류의 감소는 노 팅햄 에너지 효과에 의한 전자-정공의 교환에 관련된다 


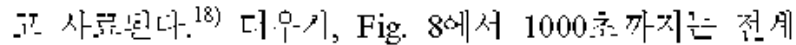

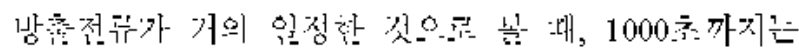

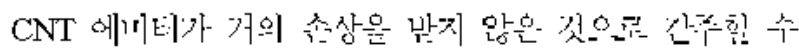

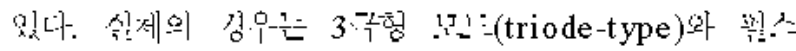

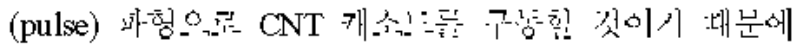

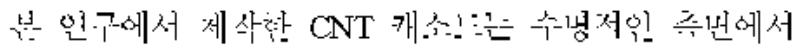

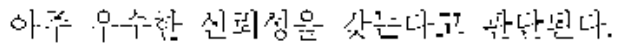

\section{4. 결 론}

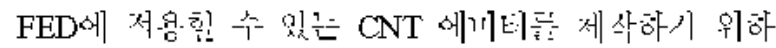

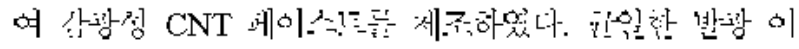

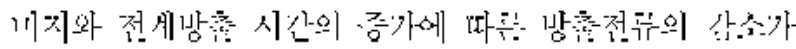

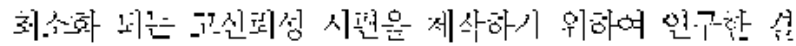
과 나음과 간흔 션론은 얻있다.

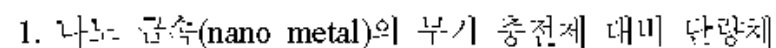

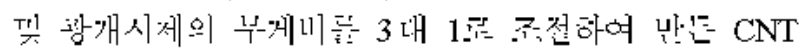

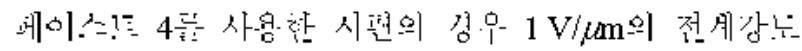

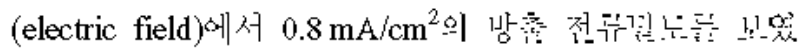

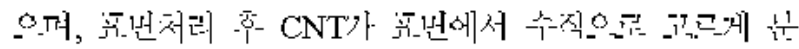

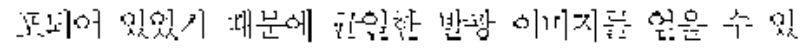
있다.

2. 최저의 소싱온나는 션정하시 위해서 TGA 눈서이 이 둥어젔으여, 1차 소싱흔 내기 분위기에서, 2차 소싱흔 진 궁 눈위이에서 신시난 $2 \mathrm{~F} 350 \mathrm{~V}$ 시편에서 가상 우운한 전

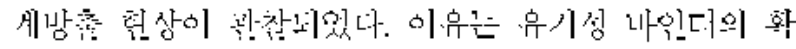

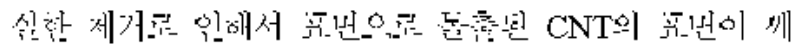

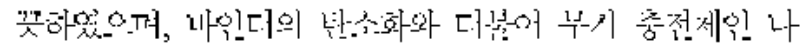

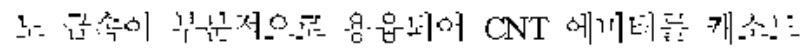
에 잔 퍼정시칬ㄱ 대분이다.

3. CNT 에끼테의 전계낭훙 련상에 내한 신뢰성 핑가

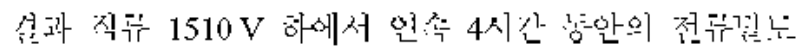

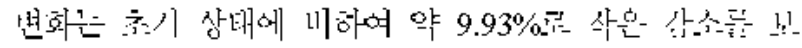

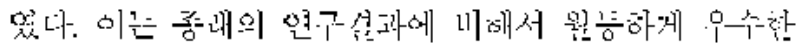

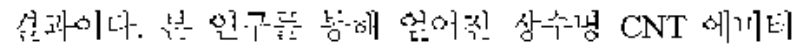

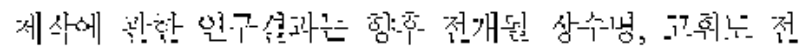

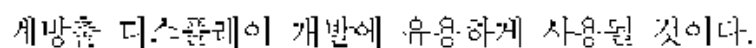

\section{참 고 문 헌}

1. Walt A. de Heer, A. Châtelain and D. Ugarte, Science 17 Nov., 270(5239), 1179 (1995).

2. S. Iijima, Nature, 354, 56 (1991)

3. W. B. Choi, D. S. Chung, J. H. Kang, H. Y. Kim, Y. W. Jin, I. T. Han, Y. H. Lee, J. E. jung, N. S. Lee, G. S. Park and J. M. Kim, Appl. Phys. Lett., 75, 3129(1999).

4. W. I. Milne, K.B.K. Teo, M. Chhowalla, P. Legagneux, G. Prio and D. Pribat, SID 2002, Digest of Technical Papers, p.1120 (2002).

5. J. -C. Ho, Y, - Y. Chang, J, -H. Liao, H. -C. Cheng, J. -R. Sheu, M, -C. Hsiao, C. -D. Lee, S. -M. Huang, C. -S. Cho, W. - K. Huang, W. -Y. Lin and C. -C. Lee, SID 2002, Digest of Technical Paper, p.372 (2002).

6. S. Kang, C. Bae, W. Son, M. H. Kim, J. Yi, S. T. A. Chang, J. J. Kim, C. R. Lee, J. H. Moon, S. H. Lim, H. S. Kim and J. Jang, SID 2003, Digest of Technical Papers, p.803 (2003).

7. Y. S. Shi, C. C. Zhu, W. Qikun and L. Xin, Diamond Relat. Mater, 12, 1449 (2003).

8. Y. R. Cho, J. H. Lee, C. S. Hwang, Y. H. Song, H. S. Uhm, D. H. Kim, S. D. Ahn, C. H. Chung, B. C. Kim and K. I. Cho, Jpn. J. Appl. Lett., 82, 3565 (2003).

9. S. K. Kang, J. H. Choi, J. H. Park, J. H. Han, J. B. You, J. W. Nam, C. K. Lee and J. M. Kim, J. Vac. Sci. Technol., B22(3) 1345 (2004).

10. D. J. Kim, Y. H. Song, J. W. Jeong, J.H. Lee and K. Y. Kang, SID 2006, Digest of Technical Paper, p.663 (2006).

11. K. B. Kim, Y. H. Song, C. H. Hwang, C. H. Chung, J. H. Lee, I. S. Choi and J. H. Park, J. Vac. Sci. Technol, B22(3) 1331 (2004).

12. J. M. Bonard, K. A. Dean, B. F. Coll and C. Klinke, Phys. Rev. Lett., 89, 197602 (2002).

13. R. H. Fowler and L. W. Nordheim, Proc. R. Soc. London, A $119,173(1928)$

14. A. S. Berdinsky, A. V. Shaporin, J. -B. Yoo, J. -H. Park, P. S. Alegaonkar, J. -H. Han and G. -H. Son, Appl. Phys., A 83, 377 (2006).

15. S. Lee, W. B. Im, J. H. Kang and D. Y. Jeon, J. Vac. Sci. Technol., B23(2) 745 (2005).

16. J. M. Kim, Field Emission Workshop'05, p.170 (2005).

17. J. H. Park, J. S. Moon, J. W. Nam, J. B. Yoo, C. Y. Park, J. M. Kim, J. H. Park, C. G. Lee and D. H. Choe, Diamond Relat. Mater, 14, 2113 (2005).

18. Y. H. Song, J. H. Lee, S. Y. Kang, Y. I. Lee, K. I. Cho and H. J. Yoo, J. Vac. Sci. Technol., B16(2) 815 (1998). 